\title{
Anakinra for the treatment of adult-onset Still's disease
}

Santos Castañeda, Belén Atienza-Mateo, José L. Martín-Varillas, José M. Serra López-Matencio \& Miguel A. González-Gay

To cite this article: Santos Castañeda, Belén Atienza-Mateo, José L. Martín-Varillas, José M. Serra López-Matencio \& Miguel A. González-Gay (2018): Anakinra for the treatment of adult-onset Still's disease, Expert Review of Clinical Immunology, DOI: 10.1080/1744666X.2018.1536548

To link to this article: https://doi.org/10.1080/1744666X.2018.1536548

Accepted author version posted online: 16

Oct 2018.

Submit your article to this journal $₫$

View Crossmark data [ 
Publisher: Taylor \& Francis

Journal: Expert Review of Clinical Immunology

DOI: $10.1080 / 1744666 X .2018 .1536548$

Article Type: Drug Profile

Anakinra for the treatment of adult-onset Still's disease

Santos Castañeda ${ }^{1}$, Belén Atienza-Mateo ${ }^{2}$, José L. Martín-Varillas ${ }^{2}$, José M. Serra López-Matencio ${ }^{1}$, Miguel A. González-Gay ${ }^{2,3,4 *}$.

\section{Affiliations:}

${ }^{1}$ Rheumatology Division, Hospital de La Princesa, IIS-Princesa, Universidad Autónoma de Madrid (UAM), Madrid, Spain.

${ }^{2}$ Epidemiology, Genetics and Atherosclerosis Research Group on Systemic Inflammatory Diseases, Rheumatology Division, Hospital Universitario Marqués de Valdecilla, IDIVAL, Santander, Spain.

${ }^{3}$ University of Cantabria, Santander, Spain

${ }^{4}$ Cardiovascular Pathophysiology and Genomics Research Unit, School of Physiology, Faculty of Health Sciences, University of the Witwatersrand, Johannesburg, South Africa.

Santos Castañeda, MD, PhD. E-mail: scastas@gmail.com

Belén Atienza-Mateo, MD. E-mail: mateoatienzabelen@gmail.com

José L. Martín Varillas, MD. E-mail:jlmvarillas@gmail.com

José M. Serra López-Matencio, PharmD. E-mail: josemaria.serra@salud.madrid.org Miguel A. González-Gay, M.D, PhD. E-mail: miguelaggay@hotmail.com

\section{*Correspondence to:}

Prof. Miguel A. González-Gay, 
University of Cantabria, Rheumatology,

Rheumatology Division,

Hospital Universitario Marqués de Valdecilla, IDIVAL, Avenida Cardenal Herrera Oria s/n 39011 - Santander, Spain.

\section{Abstract}

Introduction: Adult onset Still's disease (AOSD) is an uncommon systemic inflammatory disease on the clinical spectrum of autoinflammatory disorders. Its presentation and clinical course may result in several well differentiated phenotypes: from a systemic and highly symptomatic pattern to a chronic articular pattern. Overproduction of numerous pro-inflammatory cytokines is observed in AOSD. Anakinra (ANK), a human interleukin (IL)-1R antagonist, has recently been approved in the EU for the treatment of AOSD.

Areas covered: In this review, we discuss the main studies on the efficacy and safety on ANK for the treatment of AOSD. The vast majority of them are retrospective studies and case series.

Expert commentary: Overall, ANK is an effective biologic agent for the treatment of AOSD, especially for the systemic pattern and also for those patients who have lifethreatening complications, which frequently occur over the course of the disease. The initial dose usually indicated of ANK in adults is $100 \mathrm{mg}$ /day subcutaneously, although dose reduction can be performed in some cases once the disease is under control. The safety profile of ANK is favorable and similar to that described in other rheumatic diseases. In conclusion, ANK is an effective and safe agent for the treatment of AOSD.

Keywords: anti-IL1-receptor drugs, anakinra, adult-onset Still's disease (AOSD), biologic agents, glucocorticoids, methotrexate. 


\section{Introduction}

Adult-onset Still's disease (AOSD) is a rare systemic inflammatory disease of unknown origin affecting mainly young people with an estimated annual incidence between 0.16 and $0.4 / 100,000$ persons worldwide, independently of ethnic group [1-3]. AOSD is slightly more common in women [4,5]. Typically, there is a bimodal age distribution, with one peak between 15 and 25 years and the other one between 35 and 45 years [1]. AOSD and systemic onset juvenile idiopathic arthritis (SJIA) are considered two faces of the same disease starting at different ages. However, the majority of authors actually consider that AOSD may be categorized as a multigenic autoinflammatory disorder at the crossroads of autoinflammatory and autoimmune diseases, due to its complex pathogenesis, involving both innate and adaptive immune system [3].

The etiology of AOSD is unknown. Infectious and other environmental factors trigger a systemic autoinflammatory response in genetically predisposed individuals leading to a dysregulation of the inflammasome complex with the overproduction of numerous proinflammatory cytokines such as interleukin (IL)-1, IL-6, IL-18, interferon (IFN)- $\gamma$ and tumor necrosis factor (TNF)- $\alpha[6,7]$. Cases of AOSD associated with malignancies have also been described but this association is not common $[\mathbf{8 , 9 ]}$.

AOSD is clinically characterized by daily high spiking fever, evanescent maculopapular skin rash, arthritis, musculoskeletal symptoms, sore throat and hepatosplenomegaly. Other common manifestations include pharyngitis, lymphadenopathy, pulmonary infiltrates, pleuritis, pericarditis, myocarditis and abdominal pain $[\mathbf{3 , 1 0 , 1 1}]$. The presence of nonspecific laboratory findings is the result of a systemic inflammatory response. Patients present elevation of acute-phase reactants, such as erythrocyte sedimentation rate (ESR) and C-reactive protein (CRP), marked leukocytosis with neutrophilia, anemia, thrombocytosis, increased serum liver enzymes, mainly alanine 
and aspartate aminotransferases. Serum ferritin levels are particularly increased in AOSD (typically more than 5 times above the high limit of normal) and it may be a good marker of disease activity $[\mathbf{3 , 1 1}]$. AOSD is also associated with a reduction in the glycosylated ferritin fraction, so that the combination of serum ferritin levels higher than $1000 \mu \mathrm{g} / \mathrm{L}$ with a glycosylated fraction under $20 \%$ has been found to have a high specificity for a diagnosis of AOSD [12,13].

The presentation and clinical course of AOSD may result into three well differentiated phenotypes: a monophasic or monocyclic AOSD, characterized by a unique and selflimited flare lasting several weeks to months with subsequent resolution (30\% of cases); a systemic intermittent pattern characterized by recurrence of multiple flares with/ without joint symptoms (30\% of cases) and a chronic articular pattern, characterized by persistent polyarthritis with progressive joint destruction (around 40\%) [3,7,9]. Lifethreatening complications, with a high mortality rate, appear in around $15-20 \%$ of patients with AOSD $[\mathbf{8 , 1 4}]$. Among them, the macrophage activation syndrome (MAS) or reactive hemophagocytic syndrome (RHS) is the most severe complication [14].

Treatment of AOSD has been based on data from single clinical reports or small retrospective case series studies. Non-steroidal anti-inflammatory drugs (NSAIDs) and glucocorticoids (GC) represent the first line therapy, particularly for musculoskeletal manifestations and fever, with response rates around $20 \%$ and $60 \%$ respectively $[3,10,15]$. However, about $40-45 \%$ of patients with AOSD develop glucocorticoiddependence and mild or severe long-term side effects [16]. As a result, diseasemodifying anti-rheumatic drugs (DMARDs) such as methotrexate (MTX), azathioprine (AZA) or leflunomide (LEF), are often required as second line therapy [15-17]. In refractory cases to these treatments, biologic drugs, particularly anti-IL-1 and anti-IL-6 receptor $(\mathrm{R})$ agents, have proved to be effective to control disease activity and its 
complications $[3, \mathbf{1 8 , 1 9 , 2 0}]$. Anti-IL-6R [21-24] and TNF- $\alpha$ blocking agents $[3,15,19,20]$ have also shown to be useful in AOSD presenting with severe joint involvement [18]. In patients who are refractory to these therapies or in those with lifethreatening complications other therapies such as: intravenous immunoglobulin, cyclosporine A, cyclophosphamide or plasma exchanges can be used $[\mathbf{3 , 8 , 1 0 ]}$ (Figure 1).

Here, it is interesting to highlight the potential role of the IL-1 inhibitors (IL-1-INH) including anakinra (ANK), canakinumab (CAN) and rilonacept in the management of refractory systemic and articular clinical patterns of AOSD [25,26-30]. Anakinra is a recombinant, non-glycosylated, form of human IL-1R antagonist. Since it has a very short half-life, daily subcutaneous administrations are necessary. In contrast, CAN is a human anti-IL-1 $\beta$ monoclonal antibody with a longer half-life which can be administered every 8 weeks, while rilonacept (also known as IL-1 Trap) is a dimeric fusion protein that neutralizes IL-1 which is administered once a week. Recently, the European Commission (EC) has approved an extension of the indication for ANK (Kineret $\left.{ }^{\circledR}\right)$ to encompass the treatment of Still's disease, including SJIA and AOSD, in all 28 European Union (EU) member states

(https://www.sobi.com/en/investors/kineretr-anakinra-approved-eu-treatment-stillsdisease).

In the present review we discuss the main clinical studies performed to date that have led to the approval of ANK for the treatment of AOSD.

\section{Unmet needs in AOSD management}

Due to the low prevalence of AOSD, there are still many concerns regarding diagnosis, monitoring and treatment of the disease. There are no updated classification criteria. 
Because of that, in the clinical practice the diagnosis of AOSD is usually made by exclusion of other systemic diseases. Currently, the more commonly used criteria are those proposed by Yamaguchi et al. [31] and Fautrel et al. [32] (Table 1). The most common index used to monitor the course of the disease is the Pouchot's activity score [33]. Recently a new index known as "Relapsing Polychondritis Disease Activity Index" [34], in which 27 items are evaluated in a weighted way up to a total of 265 points according to the clinical situation in the 28 days prior to each assessment, has been proposed [34]. However, simpler indices that can be applied to daily clinical practice are still required. It is especially true since the advent of biologic agents that are now available for the management and control of this disease. With respect to this, until recently there were no specific treatment approved for this condition so the management of AOSD was considered empirical. Most information on therapy, in particular that related to the use of biologic agents, is retrospective what makes it difficult to interpret. On the other hand, ANK has not yet approved by the FDA for the indication of AOSD in the USA, where they have requested the realization of a clinical trial that is currently in progress (ClinicalTrials.gov Identifier: NCT03265132).

\section{Anakinra (ANK): main pharmacologic characteristics}

IL-1 is a pivotal pro-inflammatory cytokine that mediates many cellular responses in AOSD and in other auto-inflammatory diseases [6,7]. ANK is a non-glycosylated human interleukin-1R antagonist (IL-1ra) produced in Escherichia coli cells by recombinant DNA technology. It neutralizes the biologic activity of IL-1 $\alpha$ (IL-1 $\alpha)$ and IL-1 (IL-1 $\beta$ ) by competitively inhibiting their binding to interleukin-1 type I receptor (IL-1RI) [35]. This biologic agent was used in patients with rheumatoid arthritis (RA) with an inadequate response to MTX alone. Currently ANK is used in adults, 
adolescents, children and infants aged 8 months and older with cryopyrin-associated periodic syndromes (CAPS), including neonatal-onset multisystem inflammatory disease (NOMID)/chronic infantile neurological, cutaneous, articular syndrome (CINCA), Muckle-Wells syndrome (MWS) and familial cold autoinflammatory syndrome (FCAS) [35-40]. In April 2018, the use of ANK (Kineret $\left.{ }^{\circledR}\right)$ was approved by the EC for the treatment of Still's disease including SJIA and AOSD encompassing a spectrum of indication in adults, adolescents, children and infants aged 8 months and older with a body weight $\geq 10 \mathrm{~kg}$. In these cases, ANK can be administered as monotherapy or in combination with NSAIDs and/or DMARDs (https://www.sobi.com/en/investors/kineretr-anakinra-approved-eu-treatment-stillsdisease).

The recommended dose in AOSD for patients weighing $50 \mathrm{~kg}$ or more is $100 \mathrm{mg} /$ day by subcutaneous administration. Dose must be given according to weight in those patients weighing less than $50 \mathrm{~kg}$ with a starting dose of $1-2 \mathrm{mg} / \mathrm{kg} / \mathrm{day}$. ANK is eliminated by glomerular filtration and subsequent tubular metabolism. Consequently, plasma clearance of ANK decreases with reductions of renal function No dose adjustment is needed for patients with creatinine clearance $[\mathrm{CrCl}]$ between 60 to $89 \mathrm{ml} / \mathrm{min}$. However, it should be used with caution in patients with moderate renal impairment $(\mathrm{CrCl}$ between 30 and $59 \mathrm{ml} / \mathrm{min}$ ). Administration of ANK every other day can be used in patients with severe renal deficiency $(\mathrm{CrCl}<30 \mathrm{ml} / \mathrm{min})$ or end stage renal disease, including dialysis. Although no dose adjustment is required for patients with moderate hepatic impairment, it should be used with caution in patients with severe hepatic insufficiency [35].

Information on ANK therapy in elderly people is scarce. It comes from the RA field. Seven hundred and fifty patients with $\mathrm{RA} \geq 65$ years of age, including 163 patients $\geq 75$ 
years of age, were included in several clinical trials [35]. Overall, no differences in safety or effectiveness were observed between those $\geq 65$ years and the remaining patients. Nevertheless, since there is a higher incidence of infections in the elderly population in general, we think that we have to be especially careful at the time of prescribing ANK in elderly people. There is also limited information on the use of ANK in pregnant and lactating women. With respect to this, animal studies do not indicate reproductive toxicity. Nonetheless, ANK is not recommended in during pregnancy or in women of childbearing age not using contraception. This agent is contraindicated in patients with hypersensitivity to the active substance or to any of its excipients or to E. coli derived proteins. Furthermore, ANK treatment must not be initiated in patients with neutropenia (neutrophils $\left.<1.5 \times 10^{9} / 1\right)$ [35].

Additional information about the contraindications and adverse effects of ANK are shown in Table 2. Special mention deserves the so-called MAS. Patients with AOSD have an increased risk of spontaneous development of MAS $[\mathbf{3 , 1 1 , 1 4 ]}$. Nevertheless, during post-marketing use of ANK, case reports of MAS in ANK treated patients with AOSD have also been reported. Nonetheless, a causal relationship between ANK and MAS has not been established yet.

Regarding immunogenicity, the occurrence of antibodies was typically transient and not associated with clinical adverse reactions or loss of efficacy. In a study in patients with CAPS, the majority of patients developed ANK anti-drug antibodies [25]. However, it was not associated with any clinically significant effects on pharmacokinetics, efficacy, or safety [41]. Currently, there is not available data on the incidence of neutralizing antibodies in patients with AOSD treated with ANK.

\section{Clinical studies}


As mentioned above, IL-1 $\beta$ is one of the crucial cytokines involved in the pathogenesis of AOSD. In consequence, it is one of the main targets in the treatment of this condition $[6,7,28]$. Three IL-1 $\beta$ antagonist agents are currently available: ANK, CAN and rilonacept. Among them, ANK has been the most widely used anti-IL1 $\beta$ agent in patients with AOSD, including a randomized open-label study [42], another prospective open-label study [43], multiple retrospective studies and case series, and more than 80 case reports [44-47].

The first cases of ANK-treated AOSD refractory to other therapies were reported in 2003-2005 [44,45,48]. In 2007, two studies including 8 patients in total showed good efficacy of ANK in patients with AOSD presenting with systemic symptoms refractory to glucocorticoids, DMARDs and TNF- $\alpha$ inhibitors. Interestingly, the symptoms disappeared in a few days after the first ANK administration and the inflammatory markers returned to normal levels in 2-4 weeks. ANK therapy also allowed a fast GC tapering, although relapses occurred a few days after discontinuation of this therapy $[46,47]$.

Tables 3 and 4 show the main prospective and retrospective studies on ANK in the treatment of patients with AOSD that are discussed in the next sections.

\subsection{Prospective, randomized, active-controlled, open-label studies (Table 3)}

To our knowledge, there is only one multicenter, randomized, active-controlled, openlabel study assessing the efficacy and safety of ANK in patients with AOSD from 10 centers located in Finland, Norway, and Sweden. Patients were evaluated at 8 and 24weeks of follow-up, with an open-label extension phase of 28 weeks (until week 52) [42]. The study compared the efficacy of ANK with that of conventional DMARDs, such as MTX, AZA, and LEF, in 22 patients with AOSD [42] diagnosed according to 
the Yamaguchi's criteria [31] (Table 1). All the patients had been refractory to GC and DMARDs, defined as of presence active disease in spite of receiving prednisolone $\geq 10$ mg/day with/without concomitant DMARD or glucocorticoids plus a DMARD for $\geq 2$ months prior to randomization. The primary endpoint was remission defined as no fever in the absence of NSAIDs, decrease of CRP and ferritin levels to reach the normal range, and normal swollen and tender joint counts, after 8 weeks of treatment. All the patients initially received prednisolone $\geq 10 \mathrm{mg} /$ day and along with NSAIDs if required. ANK was subcutaneously administered at a dose of $100 \mathrm{mg} /$ day [42].

Twelve patients were randomized to ANK and 10 to DMARD (6 MTX, 2 AZA, and 2 LEF) treatment. Patient groups were comparable at baseline, except for ferritin levels and prednisolone dose, which were significantly higher in the ANK group. At the time of inclusion in the study the mean [standard deviation (SD)] age of patients in the ANK and DMARD groups was 39 (18) and 39 (17) years, respectively; the median (range) disease duration was 14 (2-240) and 19 (3-204) months in the ANK and DMARD groups, respectively (Table 3). ANK treated patients achieved remission more commonly than those receiving conventional DMARDs. Seven of 12 patients from the ANK group reached remission vs 5 of 10 patients from the DMARD group at 8 weeks. Also, 6 of 12 patients undergoing ANK therapy were in remission versus 2 of 10 patients on DMARDs group at week 24 [42]. Although differences did not reach statistical significance, more patients undergoing ANK therapy experienced improvement on physical health, as measured by the Medical Outcomes Study ShortForm 36 (SF-36), than those from the DMARD group. However, both ANK and conventional DMARD therapy allowed to perform a reduction of prednisolone dose at 24 weeks [42]. 
The study included a 28-week open-label extension phase. In this period of time switching or add-on treatment with the comparator drug was allowed if improvement had not occurred within the 24 weeks of the randomized phase. This extension phase was completed by 17 patients. At week 52, 8 of 9 patients initially treated with ANK as monotherapy persisted on treatment with this biologic agent whereas 1 of these 9 patients required MTX along with ANK. Among the 8 patients initially treated with DMARDs, 3 required additional therapy with ANK, 1 had to be switched to ANK in monotherapy and another to infliximab. Finally, at the end of the extension phase (week 52), 7 of the 14 patients treated with ANK alone or in combination with DMARDs and 2 of 3 on DMARD alone were in remission [42] (Table 3).

With respect to safety, 3 patients experienced serious adverse events (AEs) during the randomized phase, with worsening features of AOSD in 1 patient under ANK therapy and in 2 patients on DMARDs. Other AEs included flu-like symptoms, diarrhea, and myalgias. Injection site reactions (ISRs) were reported by 8 patients receiving ANK. Four additional patients reported ISR during the study extension phase.

Overall, the authors concluded that ANK induced more beneficial responses than DMARDs in patients with refractory AOSD [42].

Lequerré et al. studied the efficacy and safety of ANK treatment $(100 \mathrm{mg} / \mathrm{day})$ in 15 patients ( 4 men/11 women) with AOSD diagnosed according to the Yamaguchi's criteria [43]. At the time of ANK initiation, the patients' mean age was $38.1 \pm 12.8$ years (range: 22-62), the mean disease duration was $7.8 \pm 6.4$ years (r: 2-27), and the mean duration of GC treatment 4.6 years. DMARDs had been used in all patients and were reported as ineffective or not very effective. The mean follow-up time (range) from the onset of ANK therapy to the last follow-up was 14.3 months (r: 11-27). A rapid improvement in all disease markers, including swollen and tender joint counts, 
assessment of pain, global assessment of disease activity, ESR, and CRP levels was observed in 11 of 15 patients (73\%). Nine of these 11 patients achieved complete response (defined as a resolution of systemic symptoms and an improvement of the American College of Rheumatology [ACR] score $\geq 50 \%$ ) at 3 months and also at last follow-up, and 2 had a partial response (defined as a resolution of systemic symptoms and an improvement of the ACR score by at least $20 \%$ but less than $50 \%$ ) at 3 months and at the end of follow-up [43]. GC were discontinued in 2 of the 12 patients who were receiving this therapy at the onset of ANK treatment, and the GC dose was decreased in a range between $45 \%$ and $95 \%$ in 8 patients. Among the 12 patients initially receiving a DMARDs (MTX in 10) in combination with ANK, 7 continued receiving MTX and 1 changed to another DMARD [43].

Four patients discontinued ANK treatment, 2 due severe skin rash at 1 and 3 months, respectively, and 2 due to lack of efficacy. Other transient AEs were bronchitis, uncomplicated hepatitis A, varicella, a cutaneous infection after a piercing, osteonecrosis of the femoral hip, and pain at the injection site. One case of MAS leading to transient ANK withdrawal was also recorded [43].

\subsection{Case series and retrospective studies of patients treated with ANK (Table 4)}

This section includes retrospective studies and case series with at least 3 AOSD patients treated with ANK (Table 4).

The most important is a retrospective, nationwide, cross-sectional, observational study, which showed data from 140 Italians (93 women and 47 men) diagnosed with AOSD according to the Yamaguchi's criteria [25]. Patients were treated with ANK after failure to NSAIDs and immunosuppressive drugs, GC and DMARDs, and in some cases to other biologic agents [25]. Data were analyzed at baseline, and at 3, 6, and 12 months 
after the onset of ANK therapy. Seventy-four percent of the patients had the systemic disease (SD) pattern and 26\% the chronic articular disease (CAD) pattern. The mean disease duration before ANK onset was $4.2 \pm 6.8$ years. At baseline, $98 \%$ and $86 \%$ of patients received steroids and DMARDs, respectively. ANK was started as a first-line biologic in $79 \%$ of patients and it was prescribed in combination with DMARDs in $76 \%$, being MTX the first choice DMARD used in association with ANK in $71 \%$ of the cases [25]. The initial ANK dose was $100 \mathrm{mg} /$ day in $91 \%$ of patients. Higher doses (150-200 mg/day) were administered to 4 patients who presented with a very aggressive systemic form of the disease, and lower doses (50 mg/day or $100 \mathrm{mg}$ every other day) in 9 patients because tolerance problems. After 3, 6, and 12 months of follow-up, 118 (84\%), 109 (78\%), and 97 (69\%) patients were still receiving ANK, respectively. Overall, the mean duration of ANK treatment was $35.7 \pm 36.1$ months. At the time of data analysis, 69/140 (49\%) patients were still receiving ANK. The reasons for ANK discontinuation in the other 71 patients were the occurrence of AEs (34\% of the 71 cases), remission (sustained disappearance of all clinical and serological manifestations in $28 \%$ ), primary inefficacy (23\%), and secondary inefficacy (15\%) [25] (Table 4).

Regarding severity, the Pouchot's score significantly decreased from 5.5 \pm 1.9 (range 210) at baseline to $1.1 \pm 1.4$ (range $0-7)$ after 3 months of treatment $(\mathrm{p}<0.0001)$. The analysis of the prevalence of the disease's main clinical features and laboratory abnormalities at 3, 6, and 12 months showed a significant reduction in all these parameters $(p<0.0001)$. Serum ferritin levels were significantly reduced at 3 months compared to baseline, and reduction of CRP and ESR was also observed. The percentage of patients with hepatomegaly or increased liver enzymes decreased from $47 \%$ at baseline to $9 \%$ and $5 \%$ after 3 and 12 months of ANK treatment, respectively. Also, the percentage of patients with joint symptoms decreased from $70 \%$ at baseline to 
$33 \%$ and $14 \%$ after 3 and 12 months of ANK treatment, respectively. No differences in the clinical or serological response to treatment were identified when the patients were stratified according to age, sex, or disease phenotype (systemic or CAD pattern), or when comparing administration of ANK with or without concomitant DMARDs. The authors concluded that ANK was effective in reducing all AOSD-linked clinical and serological manifestations [25].

Primary and secondary inefficacy after 12 months of treatment were reported in 15 of $140(11 \%)$ and 11 of $140(8 \%)$ patients, respectively. Twenty patients (14\%) experienced complete remission and could discontinue ANK. Overall, ANK treatment allowed to reduce significantly the use of concomitant GC and DMARDs. In this regard, the proportion of patients receiving concomitant GC treatment decreased from $98 \%$ at baseline (mean prednisone dose $77.6 \pm 186.3 \mathrm{mg}$ ) to $86 \%$ at 3 months (mean prednisone dose $8.8 \pm 11.2 \mathrm{mg}$ ), $56 \%$ at 12 months (mean prednisone dose $3.4 \pm 4.8 \mathrm{mg}$ ), and $32 \%$ at last follow-up. The percentage of patients receiving concomitant DMARD therapy also decreased from $86 \%$ at baseline to $51 \%$ at last visit [25].

Twelve (8.5\%) patients showed signs of MAS before initiation of ANK, and 5 patients suffered a MAS during ANK treatment: two of them recovered without discontinuation of the therapy, one patient recovered and then ANK treatment was restarted while another two died, one after 12 months and the other after 16 months of treatment [25]. Other AEs were reported in 40 of 140 patients and they mainly consisted of in situ $(n=28)$ or diffuse $(n=12)$ local reactions, usually in the form of cutaneous urticarial lesions. Severe skin reactions led to ANK discontinuation in 18 cases. Seven infectious events occurred ( 3 cases of pneumonia, 3 cases of urinary tract infections, and 1 case of recurrent dental abscesses), leading to treatment discontinuation in 2 cases (Table 4). 
Vitale et al. performed a multicenter, retrospective, observational study on the use of the IL-1-inhibitor ANK in 78 patients with AOSD seen between January 2008 and July 2016 [49]. Complete response was found in $78 \%$ of patients $(61 / 78)$, and partial response in $13 \%(10 / 78)$; while treatment failure was reported in $9 \%$ of the patients (7/78). GC were given concomitantly in 66 cases (81\%) and DMARDs in 32 cases (39.5\%). Pneumonia was reported in 2 and lower limb ulcers in 1 of the patients [49] (Table 4). In this study, normalization of inflammatory markers (ESR, CRP) and the absence of all previously identified signs and symptoms of AOSD were considered as criteria for a complete response, meanwhile partial response was indicated for patients with clinical improvement but not reaching the criteria for complete response. Treatment was labelled as failing when neither clinical nor laboratory improvements were observed [49].

ANK efficacy was assessed in another multicenter, retrospective, open-label study conducted in Spain. It included 41 patients with AOSD who had failed to standard immunosuppressive therapy and in 20 cases also to at least one biological agent (mainly anti-TNF- $\alpha$ agents) [50]. At the onset of ANK, the patients' mean age was $34.4 \pm 14$ years and the median disease duration 3.5 years (interquartile range, IQR 2-6); 98\% of patients were treated with GC. ANK was prescribed as monotherapy in 12 patients or combined with other traditional DMARDs in remaining 29 patients, usually with MTX $(\mathrm{n}=24)$. The initial ANK dose was $100 \mathrm{mg} /$ day [50] (Table 4).

ANK treatment led to rapid and sustained improvement of clinical and laboratory parameters. The leukocyte count as well as the CRP, ESR, and ferritin levels were significantly decreased after 1 month of therapy and remained decreased after 12 months of treatment. The frequency of anemia also decreased from $56 \%$ at baseline to $17 \%$ and $10 \%$ at 3 and 12 months of treatment, respectively [50]. Joint manifestations 
were more refractory than systemic manifestations; however, they decreased from $88 \%$ at baseline to $42 \%$ at 3 and 12 months of ANK treatment [50]. After one year of therapy, 22 patients were still receiving $\mathrm{ANK}$ at a dose of $100 \mathrm{mg} /$ day, 3 were treated with ANK $100 \mathrm{mg} / 48 \mathrm{~h}, 1$ with ANK $100 \mathrm{mg} / 72 \mathrm{~h}$, and 1 patient received ANK every two weeks. Seven patients had discontinued ANK for lack of efficacy, 5 because of AEs, 1 because of sustained remission, and 1 due to pregnancy planning. The median dose of prednisone was reduced from $20 \mathrm{mg}$ /day (IQR: 11.3-47.5) at ANK onset to 5 mg/day (IQR 0-10) at 12 months. A significant GC sparing effect was already observed at 1 month of ANK treatment [50]. After a median follow-up of 16 months (IQR 5-50), the most common reported AEs were skin reactions $(n=8)$, leading to ANK discontinuation in 2 cases. Main data of this study are shown in Table 4 [49].

Rossi-Semerano et al. reported off-label efficacy of ANK (100 mg/day) in 35 (23 women/12 men) patients with AOSD included in a French national study [51]. Complete clinical response was achieved in $54 \%$ of them and partial response in $34 \%$. The median duration of was 461 days. Reduction of concomitant therapy was reported in 25 patients. ANK was discontinued in 20 patients because of either persistent remission $(n=1)$, lack or loss of efficacy $(n=14)$, AEs $(n=3)$, or patient request $(n=2)$. Severe AEs were reported in 3 patients (pneumonia, varicella zoster virus infection, and MAS and infection in one each). Evaluation of ANK response was not standardized in this study [51] (Table 4).

In a nationwide retrospective study conducted in France between 2009 and 2010, Giampietro et al. investigated the safety and long-term effect of ANK treatment in 28 patients (ratio men/women=1:2) with AOSD refractory to NSAIDs, GC, and DMARDs; 14 of them had previously received at least one biological agent [52] (Table 4). It is important to remark that some of them had already been included in the study by 
Lequerré et al. [43]. The mean age at the start of ANK treatment was 40.3 years and the mean disease duration 9.3 years. Thirteen (46\%) patients had a predominantly CAD, while the others had a SD pattern. ANK was initially administered at a dose of 100 $\mathrm{mg}$ /day (19 in combination with MTX). ANK was used as monotherapy in 6 patients. The main clinical characteristics of this population are shown in Table 4 [52].

In this study, all patients responded to ANK, with a rapid and sustained decrease in the GC dose. Prednisone was reduced in 15 (54\%) patients, from a mean dose of $34 \pm 22$ $\mathrm{mg} /$ day at ANK initiation to $10 \pm 8 \mathrm{mg}$ /day after 3 months. At last follow-up (mean 23 months), 16 patients were still being treated with ANK: 4 had a partial response and 12 were in complete remission. Twelve patients had discontinued ANK: 2 of them due to an insufficient response, 4 because AOSD flare after a period of complete remission, 2 because of AEs, and 1 due to pregnancy planning [52].

In another retrospective study performed in Greece [53], the efficacy and safety of ANK was evaluated in twenty-five patients (13 men and 12 women, median age 32 [range: 18-71] years, median disease duration 7 months) with Still's disease (4 patients with SJIA, and 21 with adolescent or AOSD) (Table 4). All patients had active disease resistant to GC $(n=17)$, DMARDs $(n=4)$, or TNF- $\alpha$ inhibitors $(n=4)$. Sixteen received ANK (100 mg/day) in combination with DMARDs (MTX in 13 cases), and 9 received ANK in monotherapy [53]. Oral methylprednisolone was given to 22 patients at a median dose of $4 \mathrm{mg} /$ day (range: 0-26). ANK was administered for a median time of 15 months (range: 1.5-71). Twenty patients had a follow-up time of at least 6 months and 15 patients a follow-up time greater than one year. Complete response was defined as the whole resolution of all disease-related symptoms, except for joint erosions. Partial clinical or laboratory response was defined as improvement $(\geq 10 \%$ when measurement was feasible) in $\geq 1$ related clinical or laboratory manifestations, but without complete 
resolution of disease activity [53] (Table 4). In this study, disease activity resolved completely in 21 of 25 patients (84\%) within a few days (median time 0.2 months), and the response was maintained until the last visit in all but one patient. Furthermore, a complete response of all disease-related symptoms (clinical and laboratory) occurred within a median time of 3 months in $80 \%$ of patients, while partial clinical and laboratory improvement was shown in $12 \%$ and $16 \%$ of patients, respectively. The oral GC dose was significantly reduced throughout the study and 12 patients were able to wean from GC [53]. MTX was discontinued in 3 patients 5-8 months after remission was achieved. ANK was discontinued in 8 patients in complete remission; 2 relapsed one month after treatment withdrawal, and the remaining 6 were still in remission after a median time of 6.5 months (range: 1-60 months) of treatment discontinuation. The analysis of the disease outcome in patients receiving ANK in monotherapy or in combination with a DMARD revealed no significant differences in the number of responses or in drug-related AEs [53].

Cavalli et al. retrospectively evaluated 20 patients with severe or refractory AOSD who did not respond to combination therapy with NSAIDs, GC and conventional DMARDs. They were eventually treated with at least one biological agent. Eight patients had a CAD course and 12 a SD course without chronic articular involvement [54]. Complete response was defined as the absence of articular and systemic manifestations of AOSD, with normalization of inflammatory markers (CRP and ESR) and with a $\geq 50 \%$ reduction of the GC dose for at least 2 months. Persistence of disease manifestations or the need for an additional dose of GC [prednisone $\geq 15 \mathrm{mg}$ /day] within 2 months from the initiation of a biologic was classified as treatment failure [54].

ANK represented the first-line biologic therapy in 16 cases, and was ultimately used in all patients. Sixteen of 20 patients who received ANK achieved response a few years 
after the onset of this therapy. In was especially true for the SD (11 complete responses from 12 patients; 1 patient did not respond). GC treatment was discontinued in 7 patients treated with ANK and reduced (at least 25\% dose reduction) in another 8 . Discontinuation or tapering of MTX was also possible upon clinical response in 9 patients receiving ANK. ISRs were reported in 2 patients receiving ANK [54](Table 4). In a series of patients treated with ANK, complete remission was achieved in the 11 patients who received ANK as a first-line biologic, and in 1 of 2 patients who received ANK as a second-line biologic. No severe AEs were reported. A cutaneous rash was reported in one patient treated with ANK [55].

Another retrospective observational study was conducted by Iliou et al. [10]. Ten patients resistant to GC and DMARDs were treated with ANK $100 \mathrm{mg} /$ day. Clinical remission and successful GC tapering were achieved in all of them. No major adverse events were reported [10] (Table 4).

In the chart review by Quartuccio et al, clinical and laboratory findings were evaluated in 36 patients with AOSD, 12 of whom were treated with biological agents for serious and/or refractory AOSD [56]. ANK was used in 10 of them, although only 3 patients were still being treated with ANK at last follow-up [56] (Table 4).

Naumann et al. in Germany reported 8 consecutive patients with refractory AOSD treated with ANK [57]. At the time of ANK initiation, the patients' median age was 42 years (r: 26-66) and median disease duration was 37.5 months (r: 4-139). All of them had been treated with at least one DMARD (including MTX) and 6 with anti-TNF therapy without reaching a long-lasting effect. They were responsive to high-dose GC, but flares occurred when GC were reduced to moderate or low doses. In this study, the authors stated that introduction of ANK (100 mg/day) resulted in sustained remission in all patients (duration of follow-up on ANK: 6 to 48 months) [57]. Patients experienced a 
significant improvement in clinical symptoms such as rash and arthritis within a few hours of ANK initiation. Furthermore, ANK treatment allowed a rapid tapering of GC to low doses in all patients. Although erythema at the injection site was reported in 2 patients, no severe AEs related to ANK were recorded [57] (Table 4).

Six of 57 patients with AOSD assessed in a retrospective, observational study were treated with ANK (administered along with GC in 5) [16]. Four patients had polycyclic AOSD, and 2 chronic AOSD. ANK treatment led to remission in 5 of the patients after a mean follow-up of 27.8 months. One of the patients with polycyclic AOSD experienced disease recurrence after 11 months of ANK therapy and discontinued the treatment [16].

In another study, the authors described 4 of 10 consecutive AOSD patients who required ANK (100 mg/day) because of refractory AOSD with persistent active disease despite treatment with high doses of GC [46]. Systemic symptoms disappeared within hours after the first ANK administration in all patients and laboratory values (inflammatory makers and liver enzyme levels) reverted to normal within 2-4 weeks. ANK treatment allowed GC dose tapering in all patients that were discontinued in 3 of them. Self-limiting injection site erythema was reported by all patients. No other AEs was recorded during the follow-up period (5-17 months) [46] (Table 4).

Kötter et al. (Germany) reported another case series that included 4 patients, 3 treatment-resistant AOSD patients and 1 with life-threatening disease [47]. All the patients achieved sustained remission upon ANK therapy (treatment duration 12-44 months [47]. GC were discontinued in 1 patient and the dose tapered in another 2. Severe erythema at the site of injection was reported in 1 patient [47] (Table 4).

Similar results were obtained in a case series from Canada, on 4 patients treated with ANK (100 mg/day) because of disease refractory to conventional therapies (prednisone 
in all 4, MTX in 3 and TNF- blockers in 2) [45]. The authors reported a rapid reduction (within hours to a few days after the first ANK administration) of disease activity, hematological parameters, and biochemical markers in the 4 patients. However, ANK discontinuation led to a rapid return of fever and a rise in inflammatory markers in 2 patients, with resolution following ANK reintroduction [45].

In another review, Maria et al. also reported 8 patients with refractory AOSD, 4 of them with a systemic pattern of the disease, who underwent treatment with ANK. After a median treatment duration of 24 months (range 2-57), complete or partial remission was observed in all of them [58] (Table 4).

Petryna et al. reported 3 patients with AOSD refractory to treatment with GC and DMARDs and treated successfully with another IL-1-INH, rilonacept (a long-acting IL1 Trap) [59]. Previously, all of them had been treated with ANK: In two of them with $100 \mathrm{mg}$ twice daily, achieving a partial response, whereas in the other failing to control the symptoms at ANK dose of $100 \mathrm{mg}$ /day for 6 weeks. All 3 patients were eventually switched to rilonacept [59] (Table 4).

Finally, Rech et al. described 3 patients with AOSD refractory to standard treatment (prednisolone and MTX) ANK and anti-TNF therapy. They eventually achieved remission after initiation of IL-6-blocking therapy. The authors did not mention any AE in relation to ANK treatment [60] (Table 4).

Priori et al. reported 3 patients with AOSD who had severe joint involvement and were resistant to conventional treatment [61]. ANK treatment was started $(100 \mathrm{mg} /$ day $)$ and led to improvement of joint involvement in all 3 patients ( 2 patients achieved an ACR50 and 1 an ACR20 response). GC dose was reduced in all of them [61] (Table 4).

As a limitation of this review, it is possible that some of the patients included in the studies conducted in France and Italy had been reported in more than one study. 
Taken together, the results derived from most studies indicate that ANK in AOSD, either a monotherapy or in combination with DMARDs, yields beneficial effects with rapid clinical and laboratory improvement in most patients. The use of this biologic agent allows GC tapering. In general, the safety profile of ANK in patients with AOSD is consistent with the safety data gathered from the use of ANK in patients with RA.

\section{Conclusions}

ANK is a biologic agent that has recently been approved for the treatment of AOSD. Since AOSD is an uncommon condition, most data on ANK efficacy come from retrospective reports. In this article we have reviewed the main observational studies and series of cases published on the efficacy and safety of ANK in AOSD. Data from most studies support the efficacy of ANK, both in monotherapy or in combination, especially for the systemic form of the disease when it is refractory to other more conventional therapies. Generally, a rapid and beneficial effect is observed in most cases within a few days from the beginning of ANK, allowing to reduce the dose of GC in a high percentage of patients. Nevertheless, relapses of the disease are not uncommon when the dose of prednisone falls below $10 \mathrm{mg}$ daily. The safety profile of ANK is similar to that described in other chronic inflammatory diseases in which this agent is more commonly used. It should be noted that the majority of studies on the topic carried out to date are of low quality, since they are mainly observational studies and case series.

\section{Expert commentary}

AOSD is a rare multisystemic inflammatory disease of unknown origin predominantly affecting young people. It is now included within the clinical spectrum of 
autoinflammatory disorders $[6 \mathbf{6 2 , 6 3 ]}$. Several sets of classification criteria have been developed for its diagnosis, but they lack sufficient sensitivity and specificity to be applied for individual diagnosis in clinical practice. Currently, the criteria more commonly used are those proposed by Yamaguchi et al. [31] and Fautrel et al. [32]. Several clinical phenotypes have been recognized in AOSD: a systemic pattern and a CAD [7,8,64-66]. The systemic pattern may yield more serious and life-threatening complications in the short-term, but CAD is more devastating and disabling in the longterm [14].

The ultimate goal in the management of AOSD is to control the outbreaks and to reach a sustained remission of the disease $[3,11,67]$. GC constitute the gold-standard therapy for the initial treatment of AOSD, leading to remission in around $60 \%$ of patients. Biologic therapy has to be considered in patients with AEs or in those in whom conventional therapy is not effective. Among the biologic agents currently available, IL1 and IL-6 neutralizing agents are those that have shown greater efficacy in a large number of patients $[\mathbf{2 0 , 6 7 , 6 8 ]}$.

ANK, a non-glycosylated human IL-1R antagonist, is an effective drug for the treatment of AOSD, especially for the systemic pattern of the disease. Although there is only one randomized, active-controlled, open-label study and another prospective open-label study $[\mathbf{4 2 , 4 3 ]}$, multiple retrospective studies and case series support the utility of ANK, both in monotherapy or in combination, for the treatment of refractory AOSD, especially for the systemic pattern of the disease, and also as first line of therapy for those life-threatening complications such as MAS, disseminated coagulopathy or myocarditis. ANK yields beneficial effect in a few days or weeks and allows to taper GC in a high percentage of patients. 
The initial dose usually indicated of ANK in adults is $100 \mathrm{mg} /$ day, although dose reduction by half or spacing the injection every other day or longer can be performed in some cases once the disease is under control.

There is no unanimous consensus on the method of ANK withdrawal in patients who are in remission. While it is possible to discontinue ANK in some patients with well controlled disease, the possibility of relapses has to be kept in mind. Also, although ANK was proved to be effective for the treatment of MAS, several cases of MAS were reported in patients undergoing ANK treatment. In them, the causal relationship between MAS and AOSD has not been elucidated. It is important to remark that the safety profile of ANK is globally favorable and similar to that described in other rheumatic diseases [34]. Finally, the combination of several biologic agents is not recommended for the treatment of AOSD because it may increase considerably the risk of AEs without reaching greater efficacy, as occurs in other systemic diseases.

\section{Five-year view}

In the following years, a better definition of the AOSD phenotypes will be achieved. This fact will allow the clinicians to better identity those patients who would benefit of specific biologic agents. New biomarkers on molecules that seem to play a role in the pathogenesis of the disease will help us to monitor the disease allowing the clinicians to measure the risk of relapses of the disease [69-71]. It may be the case of calprotectin [72].

Since Kineret ${ }^{\circledR}(A N K)$ has been approved in the EU for the treatment of the disease, we expect that this therapy will be used more commonly, in particular in patients with a systemic disease (SD) pattern or in those with a refractory disease. The prompt use of this biologic agent will probably reduce the risk of life-threatening complications 
associated to the disease. We foresee that the use of other molecules that also block IL-1 such as canakinumab and rilonacept will be extended. Besides anti-IL-6R antagonists that are used in some patients, in particular in those with refractory disease or with predominant CAD pattern, other biologic agents that act blocking primordial cytokines involved in the pathogenesis of the disease, such as IFN- $\gamma$ and IL-18, will be considered in some individuals with AOSD.

\section{Key issues}

- AOSD is a complex and heterogeneous disorder at halfway of autoinflammatory and autoimmune diseases.

- Although the pathogenesis of AOSD remains unknown, some key pro-inflammatory cytokines (IL-1, IL-6, IL-18, TNF $\alpha$, and IFN- $\gamma$ ) are considered to have a relevant role.

- Glucocorticoids constitute the first line of treatment for AOSD. Conventional DMARD, in particular MTX, are often considered in refractory cases or as GC sparing agents.

- Biologic agents must be considered in the management of AOSD refractory to GC and conventional DMARDs, since the ultimate goal in the management of AOSD is to achieve sustained remission and reduce the risk of relapses of the disease, avoiding lifethreatening complications.

- ANK, a human IL-1R antagonist, is an effective biologic agent for AOSD. Data from multiple retrospective studies and case series demonstrate the efficacy of ANK, both in monotherapy or in combination, for refractory AOSD, especially for the systemic pattern and in patients who experience life-threatening complications of the disease.

- Overall, the benefit/risk ratio and safety profile of ANK is favorable and similar to that described in other rheumatic diseases. Although the risk of relapses is high, withdrawal of ANK can be carried out when the disease is well controlled. 


\section{Acknowledgments}

The authors thank SOBI S.L. Spain, and especially Dr. Elena Martinez Busto, for the technical support.

\section{Funding}

This paper is not funded.

\section{Declaration of interest}

MA Gonzalez-Gay received grants/research supports from Abbvie, MSD, and Roche, and had consultation fees/participation in company sponsored speaker's bureau from Abbvie, Pfizer, Roche, Sanofi, Lilly, and Novartis. The authors have no other relevant affiliations or financial involvement with any organization or entity with a financial interest in or financial conflict with the subject matter or materials discussed in the manuscript apart from those disclosed.

\section{Reviewer disclosures}

Peer reviewers on this manuscript have no relevant financial or other relationships to disclose. 


\section{REFERENCES}

Papers of special note have been highlighted as either of interest $(\bullet)$ or of considerable interest $(\bullet)$ to readers.

[1] Magadur-Joly G, Billaud E, Barrier JH, et al. Epidemiology of adult Still's disease: estimate of the incidence by a retrospective study in west France. Ann Rheum Dis 1995;54:587-90.

[2] Evensen KJ, Nossent HC. Epidemiology and outcome of adult-onset Still's disease in Northern Norway. Scand J Rheumatol 2006;35:48-51.

[3] Castañeda S, Blanco R, González-Gay MA. Adult-onset Still's disease: Advances in the treatment. Best Pract Res Clin Rheumatol 2016;30:222-38.

- A recent review on diagnostic and therapeutic aspects of AOSD.

[4] Sampalis JS, Esdaile JM, Medsger TA Jr, et al. A controlled study of the long-term prognosis of adult Still's disease. Âm J Med 1995;98:384-8.

[5] Cagatay Y, Gul A, Cagatay A, et al. Adult-onset Still's disease. Int J Clin Pract 2009;63:1050-5.

[6] Giampietro C, Fautrel B. Anti-Interleukin-1 Agents in Adult Onset Still's Disease. Int J Inflam 2012;2012:317820.

[7] Jamilloux Y, Gerfaud-Valentin M, Martinon F, et al. Pathogenesis of adult-onset Still's disease: new insights from the juvenile counterpart. Immunol Res 2015;61:53-62.

•• Excellent review about the different pathogenic hypotheses of AOSD.

[8] Gerfaud-Valentin M, Jamilloux Y, Iwaz J, Sève P. Adult-onset Still's disease. Autoimmun Rev 2014;13:708-22. 
•• An updated and complete review of AOSD.

[9] Maria AT, Le Quellec A, Jorgensen C, et al. Adult onset Still's disease (AOSD) in the era of biologic therapies: dichotomous view for cytokine and clinical expressions. Autoimmun Rev 2014;13:1149-59.

\section{- Interesting review of the different clinical phenotypes of AOSD.}

[10] Iliou C, Papagoras C, Tsifetaki N, et al. Adult-onset Still's disease: clinical, serological and therapeutic considerations. Clin Exp Rheumatol 2013;31:47-52.

[11] Castañeda S, Vicente EF, González-Gay MA. [Adult-onset Still's disease]. Med Clin (Barc) 2016;147:217-22. Review. Spanish.

[12] Fautrel B, Le Moël G, Saint-Marcoux B, et al. Diagnostic value of ferritin and glycosylated ferritin in adult onset Still's disease. J Rheumatol 2001;28:322-9.

[13] Vignes S, Le Moël G, Fautrel B, et al. Percentage of glycosylated serum ferritin remains low throughout the course of adult onset Still's disease. Ann Rheum Dis 2000;59:347-50.

[14] Efthimiou P, Kadavath S, Mehta B. Life-threatening complications of adult-onset Still's disease. Clin Rheumatol 2014;33:305-14.

[15] Franchini S, Dagna L, Salvo F, et al. Efficacy of traditional and biologic agents in different clinical phenotypes of adult-onset Still's disease. Arthritis Rheum 2010;62:2530-5.

[16] Gerfaud-Valentin M, Maucort-Boulch D, Hot A, et al. Adult-onset still disease: manifestations, treatment, outcome, and prognostic factors in 57 patients. Medicine (Baltimore) 2014;93:91-9. 
[17] Fautrel B, Borget C, Rozenberg S, et al. Corticosteroid sparing effect of low dose methotrexate treatment in adult Still's disease. J Rheumatol 1999;26:373-8.

[18] Fautrel B, Sibilia J, Mariette X, Combe B; Club Rhumatismes et Inflammation. Tumour necrosis factor alpha blocking agents in refractory adult Still's disease: an observational study of 20 cases. Ann Rheum Dis 2005;64:262-6.

-• One of the first series of patients in whom anti-TNF agents were used in the treatment of AOSD.

[19] Kim HA, Sung JM, Suh CH. Therapeutic responses and prognosis in adult-onset Still's disease. Rheumatol Int 2012;32:1291-8.

[20] Pouchot J, Arlet J-B. Biological treatment in adult-onset Still's disease. Best Pract Res Clin Rheumatol 2012;26:477-87.

- Classic review on the use of biological therapies in the AOSD treatment.

[21] Puéchal X, DeBandt M, Berthelot J-M, et al. Tocilizumab in refractory adult Still's disease. Arthritis Care Res 2011;63:155-9.

[22] Cipriani P, Ruscitti P, Carubbi F, et al. Tocilizumab for the treatment of adult-onset Still's disease: results from a case series. Clin Rheumatol 2014;33:49-55.

[23] Elkayam O, Jiries N, Dranitzki Z, et al. Tocilizumab in adult-onset Still's disease: the Israeli experience. J Rheumatol 2014;41:244-7.

[24] Ortiz-Sanjuán F, Blanco R, Calvo-Rio V, et al. Efficacy of tocilizumab in conventional treatment-refractory adult-onset Still's disease: multicenter retrospective open-label study of thirty-four patients. Arthritis Rheumatol 2014;66:1659-65. 
[25] Colafrancesco S, Priori R, Valesini G, et al. Response to Interleukin-1 Inhibitors in 140 Italian Patients with Adult-Onset Still's Disease: A Multicentre Retrospective Observational Study. Front Pharmacol 2017;8:369.

- This is the largest retrospective observational study evaluating the efficacy and safety of IL-1 inhibitors in AOSD patients up to date.

[26] Lo Gullo A, Caruso A, Pipitone N, et al. Canakinumab in a case of adult onset Still's disease: efficacy only on systemic manifestations. Joint Bone Spine 2014;81:3767.

[27] Kontzias A, Efthimiou P. The use of canakinumab, a novel IL-1 $\beta$ long-acting inhibitor, in refractory adult-onset Still's disease. Semin Arthritis Rheum 2012;42:2015.

[28] Junge G, Mason J, Feist E. Adult onset Still's disease-The evidence that antiinterleukin-1 treatment is effective and well-tolerated (a comprehensive literature review). Semin Arthritis Rheum 2017;47:295-302.

[29] Feist E, Quartier P, Fautrel B, et al. Efficacy and safety of canakinumab in patients with Still's disease: exposure-response analysis of pooled systemic juvenile idiopathic arthritis data by age groups. Clin Exp Rheumatol 2018;36:668-75.

[30] Néel A, Wahbi A, Tessoulin B, et al. Diagnostic and management of lifethreatening Adult-Onset Still Disease: a French nationwide multicenter study and systematic literature review. Crit Care 2018;22:88.

[31] Yamaguchi M, Ohta A, Tsunematsu T, et al. Preliminary criteria for classification of adult Still's disease. J Rheumatol 1992;19:424-30.

- A set of classification criteria extensively used for the diagnosis of AOSD. 
[32] Fautrel B, Zing E, Golmard JL, et al. Proposal for a new set of classification criteria for adult-onset still disease. Medicine (Baltimore) 2002;81:194-200.

- An extremely interesting proposal for another new set of classification criteria for AOSD, which includes levels of glycosylated ferritin.

[33] Pouchot J, Sampalis JS, Beaudet F, et al. Adult Still's disease: manifestations, disease course, and outcome in 62 patients. Medicine (Baltimore) 1991;70:118-36.

[34] Arnaud L, Devilliers H, Peng SL, et al. The Relapsing Polychondritis Disease Activity Index: development of a disease activity score for relapsing polychondritis. Autoimmun Rev 2012;12:204-9.

[35] http://www.ema.europa.eu/docs/en_GB/document_library/EPAR__Product_Information/human/000363/WC500042310.pdf

- Includes all the technical data and pharmacologic characteristics of anakinra known at present.

[36] Koné-Paut I, Piram M. Targeting interleukin-1 $\beta$ in CAPS (cryopyrin-associated periodic) syndromes: what did we learn? Autoimmun Rev 2012;12:77-80.

[37] Koné-Paut I, Galeotti C. Anakinra for cryopyrin-associated periodic syndrome. Expert Rev Clin Immunol 2014;10:7-18.

[38] Landmann EC, Walker UA. Pharmacological treatment options for cryopyrinassociated periodic syndromes. Expert Rev Clin Pharmacol 2017;10:855-64.

[39] Tran TA. Muckle-Wells syndrome: clinical perspectives. Open Access Rheumatol 2017;9:123-9. 
[40] Fenini G, Contassot E, French LE. Potential of IL-1, IL-18 and Inflammasome Inhibition for the Treatment of Inflammatory Skin Diseases. Front Pharmacol $2017 ; 8: 278$.

[41] Wikén M, Hallén B, Kullenberg T, Koskinen LO. Development and effect of antibodies to anakinra during treatment of severe CAPS: sub-analysis of a long-term safety and efficacy study. Clin Rheumatol 2018 Jul 7. doi: 10.1007/s10067-018-4196-x. [42] Nordstrom D, Knight A, Luukkainen R, et al. Beneficial effect of interleukin 1 inhibition with anakinra in adult-onset Still's disease. An open, randomized, multicenter study. J Rheumatol 2012;39:2008-11.

•• It is the only open, randomized, multicenter study published on anakinra in AOSD treatment. The primary endpoint was achievement of remission at 24 weeks with an open-label extension until 52 weeks.

[43] Lequerré $\mathrm{T}$, Quartier $\mathrm{P}$, Rosellini $\mathrm{D}$, et al. Interleukin-1 receptor antagonist (anakinra) treatment in patients with systemic-onset juvenile idiopathic arthritis or adult onset Still disease: preliminary experience in France. Ann Rheum Dis 2008;67:302-8.

[44] Vasques Godinho FM, Parreira Santos MJ, Canas da Silva J. Refractory adult onset Still's disease successfully treated with anakinra. Ann Rheum Di 2005;64:647-8.

[45] Fitzgerald AA, Leclercq SA, Yan A, et al. Rapid responses to anakinra in patients with refractory adult-onset Still's disease. Arthritis Rheum 2005;52:1794-803.

[46] Kalliolias GD, Georgiou PE, Antonopoulos IA, et al. Anakinra treatment in patients with adult-onset Still's disease is fast, effective, safe and steroid sparing: experience from an uncontrolled trial. Ann Rheum Dis 2007;66:842-3. 
[47] Kötter I, Wacker A, Koch S, et al. Anakinra in patients with treatment-resistant adult-onset Still's disease: four case reports with serial cytokine measurements and a review of the literature. Semin Arthritis Rheum 2007;37:189-97.

[48] Rudinskaya A, Trock DH. Successful treatment of a patient with refractory adultonset still disease with anakinra. J Clin Rheumatol 2003;9:330-2.

[49] Vitale A, Insalaco A, Sfriso P, et al. A Snapshot on the On-Label and Off-Label Use of the Interleukin-1 Inhibitors in Italy among Rheumatologists and Pediatric Rheumatologists: A Nationwide Multi-Center Retrospective Observational Study. Front Pharmacol 2016;7:380.

[50] Ortiz-Sanjuán F, Blanco R, Riancho-Zarrabeitia L, et al. Efficacy of Anakinra in Refractory Adult-Onset Still's Disease: Multicenter Study of 41 Patients and Literature Review. Medicine (Baltimore) 2015;94:e1554.

[51] Rossi-Semerano L, Fautrel B, Wendling D, et al. Tolerance and efficacy of offlabel anti-interleukin-1 treatments in France: a nationwide survey. Orphanet J Rare Dis 2015;10:19.

[52] Giampietro C, Ridene M, Lequerre T, et al. Anakinra in adult-onset Still's disease: long-term treatment in patients resistant to conventional therapy. Arthritis Care Res (Hoboken) 2013;65:822-6.

[53] Laskari K, Tzioufas AG, Moutsopoulos HM. Efficacy and long-term follow-up of IL-1R inhibitor anakinra in adults with Still's disease: a case-series study. Arthritis Res Ther 2011;13:R91.

[54] Cavalli G, Franchini S, Aiello P, et al. Efficacy and safety of biological agents in adult-onset Still's disease. Scand J Rheumatol 2015;44:309-14. 
[55] Dall'Ara F, Frassi M, Tincani A, Airo P. A retrospective study of patients with adult-onset Still's disease: is pericarditis a possible predictor for biological diseasemodifying anti-rheumatic drugs need? Clin Rheumatol 2016;35:2117-23.

[56] Quartuccio L, Salvin S, Zuliani F, et al. Pleuritis is a red flag for adult-onset Still's disease which may require biologic therapies. Clin Exp Rheumatol 2012;30:807.

[57] Naumann L, Feist E, Natusch A, et al. IL1-receptor antagonist anakinra provides long-lasting efficacy in the treatment of refractory adult-onset Still's disease. Ann Rheum Dis 2010;69:466-7.

[58] Maria AT, Le Quellec A, Jorgensen C, et al. Adult onset Still's disease (AOSD) in the era of biologic therapies: dichotomous view for cytokine and clinical expressions. Autoimmun Rev 2014;13:1149-59.

[59] Petryna O, Cush JJ, Efthimiou P. IL-1 Trap rilonacept in refractory adult onset Still's disease. Ann Rheum Dis 2012;71:2056-7.

[60] Rech J, Ronneberger M, Englbrecht M, et al. Successful treatment of adult-onset Still's disease refractory to TNF and IL-1 blockade by IL-6 receptor blockade. Ann Rheum Dis 2011;70:390-2.

[61] Priori R, Ceccarelli F, Barone F, et al. Clinical, biological and sonographic response to IL-1 blockade in adult-onset Still's disease. Clin Exp Rheumatol 2008;26:933-7.

[62] Kastner DL, Aksentijevich I, Goldbach-Mansky R. Autoinflammatory disease reloaded: a clinical perspective. Cell 2010;140:784-90.

- A modern clinical perspective of autoinflammatory diseases supporting the need of reassessing the classification of these disorders. 
[63] Cush JJ. Autoinflammatory syndromes. Dermatol Clin 2013;31:471-80.

[64] Fujii T, Nojima T, Yasuoka H, et al. Cytokine and immunogenetic profiles in Japanese patients with adult Still's disease. Association with chronic articular disease. Rheumatology (Oxford) 2001;40:1398-404.

[65] Chen D-Y, Lan J-L, Lin F-J, Hsieh T-Y. Proinflammatory cytokine profiles in sera and pathological tissues of patients with active untreated adult onset Still's disease. J Rheumatol 2004;31:2189-98.

[66] Gerfaud-Valentin M, Sève P, Hot A, et al. [Pathophysiology, subtypes, and treatments of adult-onset Still's disease: An update]. Rev Med Interne 2015;36:319-27.

[67] Jamilloux Y, Gerfaud-Valentin M, Henry T, Sève P. Treatment of adult-onset Still's disease: a review. Ther Clin Risk Manag 2014;11:33-43.

\section{-• An elegant update of the treatment of AOSD.}

[68] Yoo DH. Treatment of adult-onset still's disease: up to date. Expert Rev Clin Immunol 2017;13:849-66.

\section{-• Another recent update on the AOSD treatment.}

[69] Girard C, Rech J, Brown M, et al. Elevated serum levels of free interleukin-18 in adult-onset Still's disease. Rheumatology (Oxford) 2016;55:2237-47.

[70] Mitrovic S, Fautrel B. New Markers for Adult-Onset Still's Disease. Joint Bone Spine 2018;85:285-93.

[71] Feist E, Mitrovic S, Fautrel B. Adult onset Still's disease: New mechanisms, biomarkers and targets. 2018 (in press). 
[72] Guo Q, Zha X, Li C, et al. Serum calprotectin--a promising diagnostic marker for adult-onset Still's disease. Clin Rheumatol 2016;35:73-9. 


\section{FIGURE LEGENDS}

Figure 1. Proposed work-up for the management of Adult-Onset Still's Disease.

Abbreviations: ANK: anakinra; AOSD: adult-onset Still's disease; AZA: azathioprine; CAN: canakinumab; DMARDs: disease-modifying antirrheumatic drugs; GC: glucocorticoids; IL: interleukin; IFX: infliximab; LEF: leflunomide; NSAIDs: nonsteroidal anti-inflammatory drugs; RLN: rilonacept; TNF- $\alpha$ : tumor necrosis factor alpha; TCZ: tocilizumab; IV: intravenous.

Adapted from references [3] and [67]. 


\section{Yamaguchi's classification criteria for diagnosis of AOSD}

Major criteria:

1. Fever $\geq 39^{\circ} \mathrm{C}$ lasting at least 1 week

2. Arthralgia or arthritis lasting $\geq 2$ weeks

3. Typical nonpruritic salmon-pink skin rash

4. Leukocytosis $\geq 10,000 / \mathrm{mm}^{3}$ with granulocytes $\geq 80 \%$

Minor criteria:

1. Sore throat

2. Lymph node enlargement

3. Hepatomegaly or splenomegaly

4. Abnormal liver function tests

5. Negative ANA and RF tests

Exclusion criteria:

1. Infections

2. Malignancy (mainly malignant lymphoma)

3. Other systemic disorders (mainly vasculitis)

( $\geq 5$ criteria are required with at least 2 being major criteria and no exclusion criteria)

\section{Fautrel's classification criteria for diagnosis of AOSD}

Major criteria:

1. Spiking fever $\geq 39^{\circ} \mathrm{C}$

2. Arthralgias 
3. Transient erythema

Table

4. Pharyngitis

1.

5. Polymorphonuclear cells $\geq 80 \%$

Classif ication

6. Glycosylated ferritin $\leq 20 \%$

criteria

for the

diagno

sis of

1. Maculopapular rash

adult-

2. Leukocytosis $>10,000 / \mathrm{mm}^{3}$

onset

( $\geq 4$ major criteria or 3 major +2 minors are required)

Still's

diseas

e

proposed by Yamaguchi in 1992 [31] and Fautrel in 2002 [32]. 
Abbreviations: AOSD: adult-onset Still's disease; ANA: antinuclear antibodies; RF: rheumatoid factor. 
Table 2. Main undesirable effects of anakinra according to MedDRA Organ System classification.

\section{MedDRA Organ System $\quad$ Frequency* Undesirable Effects}

\begin{tabular}{|c|c|c|}
\hline \multirow{2}{*}{$\begin{array}{l}\text { Skin and subcutaneous tissue } \\
\text { disorders }\end{array}$} & Very common & Injection site reaction \\
\hline & Uncommon/common $\$$ & Rash \\
\hline Nervous system disorders & Very common & Headache \\
\hline Metabolic disorders & Very common & Blood cholesterol increased \\
\hline \multirow[t]{2}{*}{ Infections and infestations } & Common & $\begin{array}{l}\text { Bacterial infections } \\
\text { (cellulitis, pneumonia, bone } \\
\text { and joint infections) }\end{array}$ \\
\hline & Uncommon & $\begin{array}{l}\text { Opportunistic infections } \\
\text { (fungal, mycobacterial, viral) }\end{array}$ \\
\hline $\begin{array}{l}\text { Blood and lymphatic system } \\
\text { disorders }\end{array}$ & Common & $\begin{array}{l}\text { Neutropenia } \\
\text { Thrombocytopenia }\end{array}$ \\
\hline Immune system disorders & 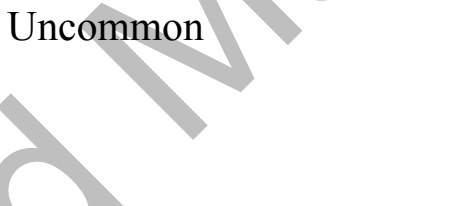 & $\begin{array}{l}\text { Allergic reactions including } \\
\text { anaphylactic reactions, } \\
\text { angioedema, urticaria and } \\
\text { pruritus }\end{array}$ \\
\hline \multirow[t]{2}{*}{ Hepatobiliary disorders } & $\mathrm{n}$ & Hepatic enzyme increased \\
\hline & $\begin{array}{l}\text { Not known } \\
\text { (cannot be estimated from } \\
\text { the available data) }\end{array}$ & Non-infectious hepatitis \\
\hline
\end{tabular}

Abbreviations: MedDRA: Medical Dictionary for Regulatory Activities.

Adverse reactions are listed according to MedDRA system organ class and frequency category. * Frequency categories are defined using the following convention: very common $(\geq 1 / 10)$; common $(\geq 1 / 100$ to $<1 / 10)$; uncommon $(\geq 1 / 1,000$ to $<1 / 100)$; rare $(\geq 1 / 10,000$ to $<1 / 1,000)$; very rare $(<1 / 10,000)$; not known (cannot be estimated from the available data). Most of the results shown in the table are obtained from placebocontrolled studies performed in patients with rheumatoid arthritis and from open-label studies in patients with cryopyrin-associated periodic syndromes. ${ }^{\$}$ Between uncommon and common depending on MedDRA and the clinical series published. 
Modified from ref. [35].

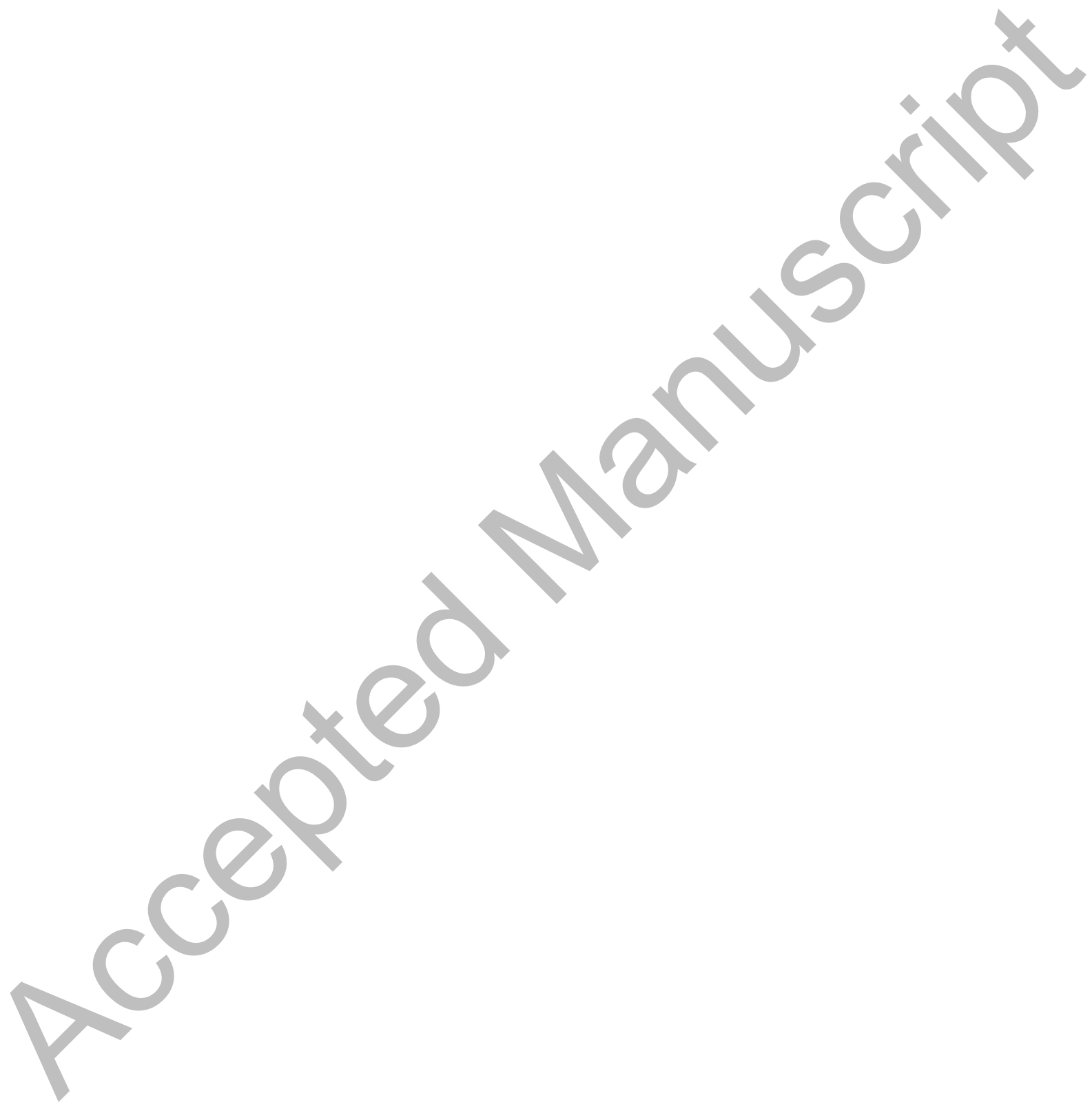


Table 3. Published randomized, controlled trial and prospective study of anakinra use in patients with adult-onset Still's disease.

\begin{tabular}{|c|c|c|c|c|c|}
\hline $\begin{array}{l}\text { Study } \\
\text { (Country) } \\
\text { [Ref. number] }\end{array}$ & $\begin{array}{l}\text { Number of } \\
\text { patients } \\
\text { (Sex) }\end{array}$ & $\begin{array}{l}\text { Treatment } \\
\text { duration }\end{array}$ & $\begin{array}{l}\text { Complete } \\
\text { response }^{1}\end{array}$ & $\begin{array}{l}\text { Partial } \\
\text { response }^{1}\end{array}$ & No response $^{1}$ \\
\hline
\end{tabular}

\section{Prospective, randomized, active-controlled, open-label study}

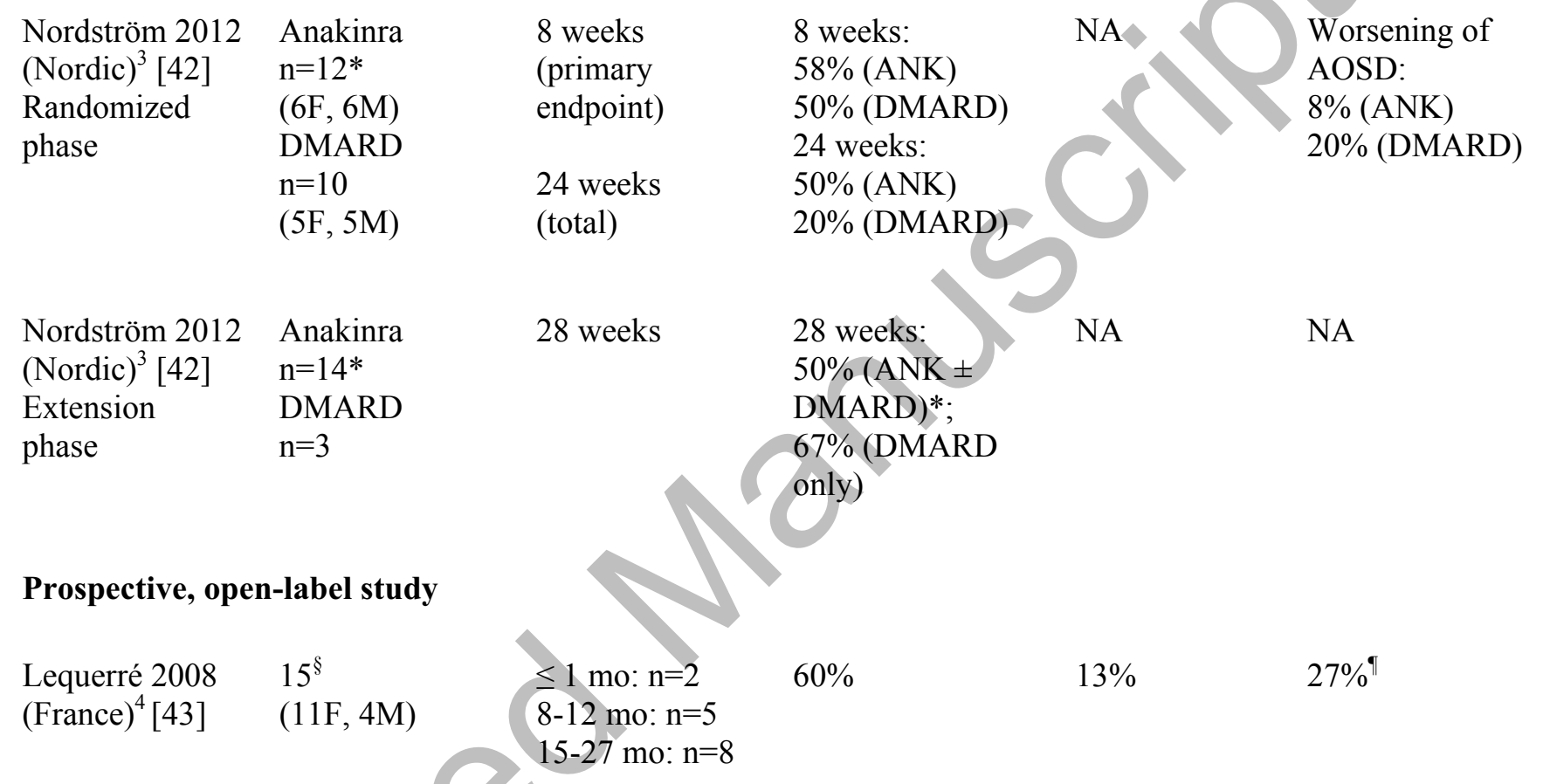

Abbreviations: ANK: anakinra (IL-1R antagonist monoclonal antibody); DMARD: diseasemodifying anti-rheumatic drugs; F: female; FH: femoral hip; ISR: injection site reaction; M: male; MAS: macrophage activation syndrome; mo: month; NA: not available; NNS: number not specified; SAE: serious adverse event.

${ }^{1}$ As reported in the publication; assessment of response to treatment and definition of complete/partial/no response vary among studies, see text for more information on treatment response in each study.

${ }^{2}$ In patients treated with ANK and as reported in the publication.

${ }^{3}$ Nordic $=$ Finland, Norway, Sweden.

${ }^{4}$ Patients included in this study were also identified for inclusion in the Giampietro 2013 retrospective study [50], which is shown in Table 4. It is however not specified whether all or only a subset of these patients was included in Giampietro 2013 study [50].

*According to the publication, 12 patients received ANK treatment in the randomized phase, 9 
of these patients continued ANK treatment in the extension phase, and 4 patients who received DMARD treatment in the randomized phase started ANK treatment in the extension phase. However, the authors also state that at 52 weeks 14 patients had ANK in monotherapy or ANK/DMARD in combination, with 7 out of 14 patients in remission.

$\S$ All treated with ANK.

『 Two out of 4 patients classified as non-responders here discontinued ANK after 1 and 3 months because of a skin rash.

For more information on the studies included in this Table see commentaries in the text. 
Table 4. Published case series and retrospective studies of anakinra use in patients with adult-onset Still's disease.

\begin{tabular}{|c|c|c|c|c|c|c|}
\hline $\begin{array}{l}\text { Study } \\
\text { (Country) } \\
\text { [Ref. number] }\end{array}$ & $\begin{array}{l}\text { Number of } \\
\text { patients } \\
\text { (Sex) }\end{array}$ & $\begin{array}{l}\text { ANK treatment } \\
\text { duration }\end{array}$ & $\begin{array}{l}\text { Complete } \\
\text { response }^{1}\end{array}$ & $\begin{array}{l}\text { Partial } \\
\text { response }^{1}\end{array}$ & No response ${ }^{1}$ & $\begin{array}{l}\text { Glucocorticoid } \\
\text { use }\end{array}$ \\
\hline $\begin{array}{l}\text { Colafrancesco } \\
2017 \text { (Italy) }^{3} \\
{[25]^{\$}}\end{array}$ & $\begin{array}{l}140 \\
(93 \mathrm{~F}, 47 \mathrm{M})\end{array}$ & $\begin{array}{l}<3 \text { mo: } n=22 \\
3-6 \text { mo: } n=9 \\
\text { 6-12 mo: } n=12 \\
\geq 12 \text { mo: } n=97\end{array}$ & $\begin{array}{l}\text { NA } \\
\text { (Complete } \\
\text { remission \& } \\
\text { ANK } \\
\text { withdrawal } \\
\text { in } 14 \% \text { ) }\end{array}$ & & $\begin{array}{l}\text { Lack /loss of } \\
\text { efficacy at } 12 \\
\text { months: }\end{array}$ & $\begin{array}{l}\text { Baseline: } 98 \% \\
\text { At } 12 \text { mo: } 56 \% \\
\text { (dose reduced) }\end{array}$ \\
\hline $\begin{array}{l}\text { Vitale } 2016^{4} \\
{[49]}\end{array}$ & $\begin{array}{l}78 \\
\text { (NA) }\end{array}$ & NA & $78 \%$ & $13 \%$ & & NA \\
\hline $\begin{array}{l}\text { Ortiz-Sanjuán } \\
2015 \text { (Spain) } \\
{[50]^{\$}}\end{array}$ & $\begin{array}{l}41 \\
(26 \mathrm{~F}, 15 \mathrm{M})\end{array}$ & $\begin{array}{l}<3 \text { mo: } n=4 \\
3-6 \text { mo: } n=5 \\
6-12 \text { mo: } n=5 \\
\geq 12 \text { mo: } n=27\end{array}$ & NA & & $\begin{array}{l}\text { Lack of } \\
\text { efficacy } \\
\text { at } 12 \text { mo: } \\
17 \%\end{array}$ & Dose reduced \\
\hline $\begin{array}{l}\text { Rossi- } \\
\text { Semerano } 2015 \\
4,5[51]\end{array}$ & $\begin{array}{l}35 \\
(23 \mathrm{~F}, 12 \mathrm{M})\end{array}$ & $\begin{array}{l}\text { Median } 15 \mathrm{mo} \\
\text { (IQR } 38 \mathrm{mo} \text { ) }\end{array}$ & & $34 \%{ }^{\S}$ & $9 \% §$ & $\begin{array}{l}\text { Dose } \\
\text { reduced }\end{array}$ \\
\hline $\begin{array}{l}\text { Giampietro } \\
2013 \text { (France) }{ }^{3,} \\
{ }^{6}[52]\end{array}$ & $\begin{array}{l}28 \\
(19 \mathrm{~F}, 9 \mathrm{M})\end{array}$ & $\begin{array}{l}<3 \text { mo: } \mathrm{n}=4 \\
\text { At last follow-up } \\
\text { (mean } 23 \mathrm{mo} \text { ): }\end{array}$ & $57 \%$ & $29 \%$ & $\begin{array}{l}\text { Loss of } \\
\text { efficacy: } \\
14 \%\end{array}$ & $\begin{array}{l}\text { Dose reduced } \\
\text { in } 54 \% \text { at } 3 \\
\text { months }\end{array}$ \\
\hline $\begin{array}{l}\text { Laskari } 2011 \\
(\text { Greece })^{7}[53]\end{array}$ & $\begin{array}{l}25 \\
(12 \mathrm{~F}, 13 \mathrm{M})\end{array}$ & $\begin{array}{l}\text { Median } 15 \mathrm{mo} \\
\text { (range } 1.5-71 \mathrm{mo} \text {; } \\
\text { at least } 6 \text { months } \\
\text { in } 20 \text { patients) }\end{array}$ & $80 \%$ & $12 \%$ & $\begin{array}{l}\text { Lack/loss of } \\
\text { response: } \\
4 \% / 4 \%\end{array}$ & $\begin{array}{l}\text { Dose reduced; } \\
\text { Stopped in } \\
12 / 22\end{array}$ \\
\hline Cavalli 2015 & $\begin{array}{l}20 \\
(11 \mathrm{~F}, 9 \mathrm{M})\end{array}$ & $\begin{array}{l}3-6 \text { mo: } n=4 \\
16-36 \text { mo: } n=5 \\
48-66 \text { mo: } n=6 \\
72-102 \text { mo: } n=5\end{array}$ & $70 \%$ & $10 \%$ & $20 \%$ & $\begin{array}{l}\text { Dose } \\
\text { reduced in } 8 \\
\text { Stopped in } 7\end{array}$ \\
\hline $\begin{array}{l}\text { Dall'Ara } 2016 \\
\text { [55] }\end{array}$ & $\begin{array}{l}13 \\
\text { (NA) }\end{array}$ & $\begin{array}{l}12 \text { mo: } n=2 \\
48-61 \text { mo: } n=6 \\
\text { 93-102 mo: } n=3 \\
\text { Unspecified: } n=2\end{array}$ & $92 \%$ & $8 \%$ & $0 \%$ & NA \\
\hline
\end{tabular}




\begin{tabular}{|c|c|c|c|c|c|}
\hline $\begin{array}{l}\text { Iliou } 2013 \\
(\text { Greece })^{7}[10]\end{array}$ & $\begin{array}{l}10 \\
\text { (NA) }\end{array}$ & NA & $\begin{array}{l}\text { Overall } \\
\text { response: } \\
100 \%\end{array}$ & $0 \%$ & $\begin{array}{l}\text { Dose tapering } \\
\text { in all patients }\end{array}$ \\
\hline $\begin{array}{l}\text { Quartuccio } \\
2012[56]\end{array}$ & 10 & NA & NA & $\begin{array}{l}\text { Lack/loss } \\
\text { of response } \\
\text { in } 1\end{array}$ & NA \\
\hline $\begin{array}{l}\text { Naumann } 2010 \\
\text { (Germany) }^{7} \\
{[57]}\end{array}$ & $\begin{array}{l}8 \\
(7 \mathrm{~F}, 1 \mathrm{M})\end{array}$ & $\begin{array}{l}\text { 6-12 mo: } n=4 \\
36-48 \text { mo: } n=4\end{array}$ & $\begin{array}{l}\text { Overall } \\
\text { response: } 100 \%\end{array}$ & $0 \%$ & $\begin{array}{l}\text { Tapering to } \\
\text { low dose in all }\end{array}$ \\
\hline $\begin{array}{l}\text { Gerfaud- } \\
\text { Valentin } 2014 \\
{[16]}\end{array}$ & $\begin{array}{l}6 \\
\text { (NA) }\end{array}$ & $\begin{array}{l}\text { Mean follow-up } \\
28 \text { months }\end{array}$ & $\begin{array}{l}\text { Overall response: } \\
83 \%\end{array}$ & $\begin{array}{l}\text { Loss of } \\
\text { response } \\
\text { in only one }\end{array}$ & NA \\
\hline $\begin{array}{l}\text { Kalliolias } 2007 \\
(\text { Greece })^{7}[46]\end{array}$ & $\begin{array}{l}4 \\
(1 F, 3 M)\end{array}$ & Range 5-17 mo & $\begin{array}{l}\text { Overall } \\
\text { response: } 100 \%\end{array}$ & $0 \%$ & $\begin{array}{l}\text { Tapering in all } \\
\text { Stopped in } 3 / 4\end{array}$ \\
\hline $\begin{array}{l}\text { Kötter } 2007 \\
\text { (Germany) }^{7} \\
{[47]}\end{array}$ & $\begin{array}{l}4 \\
(3 \mathrm{~F}, 1 \mathrm{M})\end{array}$ & $\begin{array}{l}12-15 \text { mo: } n=3 \\
44 \text { mo: } n=1\end{array}$ & $\begin{array}{l}\text { Overall } \\
\text { response }\end{array}$ & $0 \%$ & $\begin{array}{l}\text { Tapering in } 2 / 4 \\
\text { Stopped in } 1 / 4\end{array}$ \\
\hline $\begin{array}{l}\text { Fitzgerald } 2005 \\
\text { (Canada) }[45]\end{array}$ & $\begin{array}{l}4 \\
(2 \mathrm{~F}, 2 \mathrm{M})\end{array}$ & Range 6-14 mo & $0 \%$ & & Stopped in $3 / 4$ \\
\hline $\begin{array}{l}\text { Maria } 2014 \\
{[58]}\end{array}$ & $\begin{array}{l}4 \\
\text { (NA) }\end{array}$ & $\begin{array}{l}\text { Median } 24 \mathrm{mo} \\
\text { (range } 2-57 \mathrm{mo} \text { ) }\end{array}$ & $75 \%$ & $0 \%$ & NA \\
\hline $\begin{array}{l}\text { Petryna } 2012 \\
\text { (USA) [59] }\end{array}$ & $\begin{array}{l}3 \\
(3 F)\end{array}$ & $\begin{array}{l}6 \text { weeks: } n=1 \\
\text { Unknown: } n=2\end{array}$ & $67 \%$ & $33 \%$ & NA \\
\hline $\begin{array}{l}\text { Rech } 2011 \\
\text { (Germany) }^{7} \\
{[60]}\end{array}$ & 3 & Range 1-6 mo & $0 \%$ & $100 \%$ & NA \\
\hline $\begin{array}{l}\text { Priori } 2008 \\
{[61]}\end{array}$ & $\begin{array}{l}3 \\
(3 F)\end{array}$ & $\begin{array}{l}8 \text { weeks: } n=1 \\
12 \text { mo: } n=1 \\
29 \text { mo: } n=1\end{array}$ & $\begin{array}{l}\text { Overall } \\
\text { response: } \\
100 \%\end{array}$ & $\begin{array}{l}\text { Dose } \\
\text { reduced } \\
\text { in all }\end{array}$ & $\begin{array}{l}\text { Skin reaction } \\
(\mathrm{n}=1)\end{array}$ \\
\hline
\end{tabular}

Abbreviations: AEs: adverse events; ANK: anakinra (IL-1R antagonist monoclonal antibody); F: female; IQR: interquartile range; ISRs: injection site reactions; M: male; MAS: macrophage activation syndrome; mo: month; NA: not available; NR: not reported.

${ }^{1}$ As reported in the publication; assessment of response to treatment and definition of complete/partial/no response vary among studies. See text for more information on treatment response in each study; if the study does not specifically mention "complete" or "partial" response, the proportion of responders is indicated as "overall response". 
${ }^{2}$ In patients treated with ANK and as reported in the publication; NR: no AE reported, however the absence of AEs is not clearly stated either.

${ }^{3}$ It is possible that some of the patients included in all the studies conducted in France and Italy had been reported in more than one study. However, as the publications do not specifically mention how many patients were already reported, and in what studies, it is not possible to clearly identify the extent of redundant reporting. For more information on the studies included in this Table see commentaries in the text.

${ }^{4}$ Considering the nationwide/multicentre and retrospective nature of the studies by Vitale 2016 [49] and Rossi-Semerano 2015 [51], it is probable that they include some or all of the patients already reported in Dall'Ara 2016 [55], Cavalli 2015 [54], Quartuccio 2012 [56], and Priori 2008 [61]; and Gerfaud-Valentin 2014 [16] and Maria 2014 [58], respectively.

${ }^{5}$ The Rossi-Semerano 2015 study [51] includes more patients with AOSD than the Giampietro 2013 study [52]. However, as the Giampietro 2013 study [52] focuses solely on AOSD patients and provides more detailed data on patient population and outcomes, it is presented as the main retrospective study for France.

${ }^{6}$ Some of the patients included in Lequerré 2008 study [43] (Table 3) were identified for inclusion in the Giampietro 2013 retrospective study [52]. It is however not specified whether all or only a subset of these patients were included in Giampietro 2013 study [52]; mean followup in Lequerré 2008 study [43] was 14 months, versus 23 months in Giampietro 2013 study [52].

${ }^{7}$ The Greek and German studies shown in this table were conducted at different hospitals in different cities and therefore likely present non-overlapping patient populations.

${ }^{\$}$ Both the Colafrancesco [25] and Ortiz-Sanjuán [50] studies report the proportions of patients experiencing a lack or loss of efficacy but do not clearly state the proportion of patients with response to ANK treatment.

* Other adverse events are reported in the overall study, however the diagnosis of the patients in whom these adverse events occurred is not specified.

$\S$ Clinical response; data not available in 1 patient; besides reporting the clinical response rates, the authors also indicate that 14 (40\%) patients discontinued ANK because of lack or loss of efficacy. " Levels of Evidence according to the Oxford Centre for Evidence-based Medicine (March 2009).

For more information on the studies included in this Table see commentaries in the text. 


\section{Figure 1}

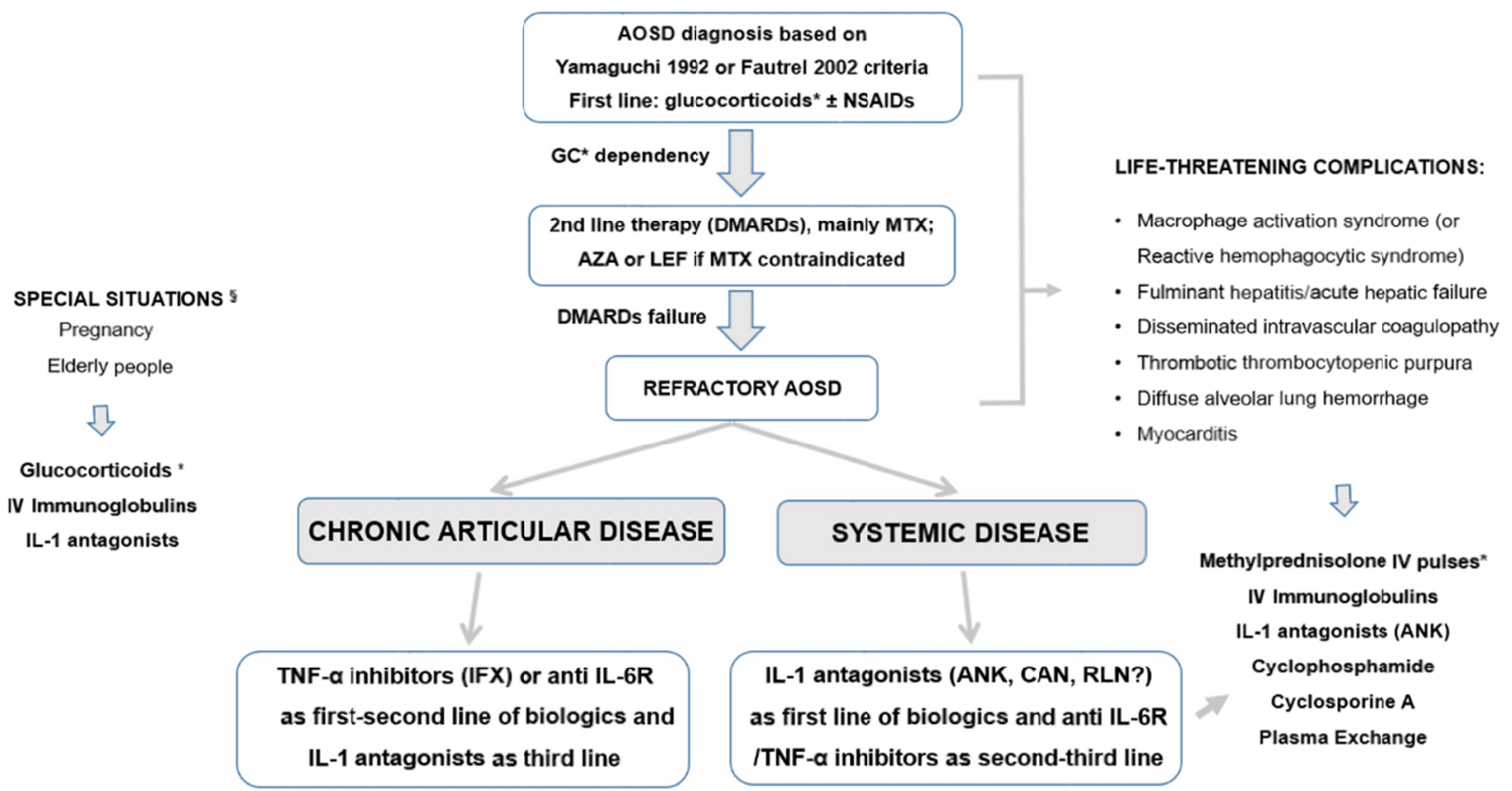

* If glucocorticoids are required at high dose or for a long-term, bone densitometry \& osteoprotective measurements to prevent fractures should be considered.

5 Individual evaluation in every case. Adapted from references [3] and [67]. 